\title{
Proton pump inhibitors suppress absorption of dietary non- haem iron in hereditary haemochromatosis
}

\author{
Carol Hutchinson, Catherine A Geissler, Jonathan J Powell, Adrian Bomford
}

Gut 2007;56:1291-1295. doi: 10.1136/gut.2006.108613

See end of article for authors' affiliations

Correspondence to

$\operatorname{Dr}$ A Bomford, Institute of

Liver Studies, King's College

Hospital, Denmark Hill,

London SE5 9RS, UK;

adrian.bomford@kcl.ac.uk

Revised 26 January 2007

Accepted 28 February 2007

Published Online First

30 April 2007
Background and Aims: During the long-term treatment of patients with hereditary haemochromatosis $(\mathrm{HH})$ the authors observed that proton pump inhibitors (PPI) reduced the requirement for maintenance phlebotomy. Gastric acid plays a crucial role in non-haem iron absorption and the authors performed a case review and intervention study to investigate if PPI-induced suppression of gastric acid would reduce dietary iron absorption in C282Y homozygous patients.

Methods: Phlebotomy requirements to keep serum ferritin $\sim 50 \mu \mathrm{g} / \mathrm{l}$ before (mean 6.1 (SE 0.6) years) and during (3.8 (0.9) years) administration of a PPI were evaluated in seven patients and a post-prandial study was performed to determine whether PPIs reduce absorption of non-haem iron $(14.5 \mathrm{mg})$ from a test meal in a further 14 phlebotomised patients with normal iron stores.

Results: There was a significant reduction $(p<0.001)$ in the volume of blood removed annually before $(2.5$ (0.25) I) and while taking (0.5 (0.25) I) a PPI. Administration of a PPI for 7d suppressed absorption of nonhaem iron from the meal as shown by a significant reduction (all $p<0.01$ ) in: area under the serum curve $(2145(374)$ versus $1059(219)), \%$ recovery of administered iron at peak serum iron $(20.5$ (3.2) versus 11.0 (2.0)\%) and peak serum iron (13.6 (2.4) vs 6.1 (1.2) $\mu \mathrm{mol} / \mathrm{l}$ ) (all values are before vs during PPI).

Conclusions: Administration of a PPI to patients with $\mathrm{HH}$ can inhibit the absorption of non-haem iron from a test meal and the habitual diet.
$\mathrm{T}$ he phenotype of HFE-related hereditary haemochromatosis $(\mathrm{HH})$ results from the progressive accumulation of iron in the parenchymal cells of the liver, pancreas, anterior pituitary and cardiac myocytes, and in the absence of treatment to reduce body iron levels a characteristic picture of tissue injury and organ failure develops. ${ }^{12}$ The mainstay of treatment consists of repeated phlebotomy to induce negative iron balance and remove excess iron stored in the tissues. Introduced as a treatment over 50 years ago, ${ }^{3}$ this has proved to be a highly effective means of removing excess iron and preventing further iron accumulation in the tissues following removal of the initial iron burden. ${ }^{4-6}$ Importantly, if iron stores are removed before tissue damage in the form of cirrhosis or diabetes has supervened, then organ failure can be prevented and life expectancy is normal. ${ }^{7}$ However, phlebotomy provides a powerful stimulus to iron absorption and following removal of tissue storage iron at diagnosis, long-term maintenance phlebotomy with the removal of $\sim 1.8-2.4$ l (3-4 units of blood) annually, equivalent to $\sim 0.75-$ $1.0 \mathrm{~g}$ of iron, is required to keep iron stores within normal limits. ${ }^{89}$

Other methods of preventing or reducing the rate of iron reaccumulation in $\mathrm{HH}$ are not routinely practised even though dietary intervention appears to have the potential to limit dietary iron absorption. For example, polyphenols supplied by drinking tea resulted in a $70 \%$ reduction in the absorption of non-haem iron from a test meal in a group of $\mathrm{HH}$ patients. ${ }^{10}$ Gastric acid production is also known to be an important factor in ensuring optimum conditions for the absorption of nonhaem iron ${ }^{11}$ and in a recent case report, two anaemic patients failed to respond to oral iron treatment while taking proton pump inhibitor (PPI) but iron status improved when the PPI was withdrawn. ${ }^{12}$ In an early study, it was reported that a single dose of cimetidine, an $\mathrm{H}_{2}$-histamine receptor antagonist $\left(\mathrm{H}_{2} \mathrm{RA}\right)$, resulted in a significant reduction in the absorption of non-haem iron from a test meal in controls and patients with idiopathic haemochromatosis. ${ }^{13}$ However, there are reasons to revisit this issue. Firstly, the impact that suppression of gastric acid has on the absorption of non-haem iron has not been assessed in $\mathrm{HH}$ patients homozygous for the $\mathrm{C} 282 \mathrm{Y}$ mutation. Secondly, despite their widespread use long-term pharmacological suppression of gastric acid with PPIs is not associated with an increased risk of iron deficiency anaemia, ${ }^{14}{ }^{15}$ possibly because individuals with normal regulatory mechanisms governing iron absorption are able to adapt to reduced bioavailability of non-haem iron by upregulating absorption. Thirdly, PPIs offer a greater degree of acid suppression than $\mathrm{H}_{2} \mathrm{RA}$ and are widely used in the treatment of acid-peptic disease in primary care.

The present study was prompted by our observation that patients taking a PPI or $\mathrm{H}_{2} \mathrm{RA}$ had a reduced requirement for maintenance phlebotomy. A case review of patients with haemochromatosis undergoing maintenance phlebotomy at this institution was conducted to evaluate the potential effect of these agents on iron re-accumulation. A comparison of paired data was made in a group of patients where phlebotomy records were available for a substantial period when no acid suppressant agents were taken, and then, during a subsequent period following administration of a PPI. A further group of patients who had never taken a PPI was also studied. The case review was followed by an intervention study of post-prandial iron absorption in fully treated patients with $\mathrm{HH}$ before and during administration of a PPI to look for evidence that these agents reduce the absorption of dietary non-haem iron.

\section{PATIENTS AND METHODS}

These studies were approved by the Local Research Ethics Committee of King's College Hospital and patients gave their informed consent.

Abbreviations: AUC, area under the serum iron curve; $\mathrm{HCl}$, hydrochloric acid; $\mathrm{HH}$, hereditary haemochromatosis; $\mathrm{H}_{2} \mathrm{RA}, \mathrm{H}_{2}$-histamine receptor antagonist; NSAIDs, non-steroidal anti-inflammatory drugs; PPI, proton pump inhibitor 
Table 1 Phlebotomy requirements and iron indices in 7 patients before and during PPI treatment (paired) and in 8 patients not prescribed a PPI (unpaired)

\begin{tabular}{|c|c|c|c|c|c|c|}
\hline & \multicolumn{3}{|c|}{ Paired group $(n=7)$} & \multicolumn{3}{|c|}{ Unpaired group $(n=8)$} \\
\hline & Before PPI & During PPI & p Value & & p Valuet & p Valueł \\
\hline $\begin{array}{l}\text { Recording period (years) } \\
\text { Haemoglobin }(\mathrm{g} / \mathrm{d}) \text { ) } \\
\text { Serum ferritin }(\mu \mathrm{g} / \mathrm{l}) \\
\text { Annual phlebotomy } \\
\text { requirements (litres) }\end{array}$ & $\begin{array}{l}6.1(0.2)^{\star} \\
14(0.2) \\
81.4(17.1) \\
2.5(0.2)\end{array}$ & $\begin{array}{r}3.8(0.9) \\
14.3(0.4) \\
38.5(8.5) \\
0.5(0.2)\end{array}$ & $\begin{array}{l}0.2 \mathrm{NS} \\
0.6 \mathrm{NS} \\
0.1 \mathrm{NS} \\
<0.001\end{array}$ & $\begin{array}{r}7.8(1.5) \\
13.5(0.3) \\
55.3(4.7) \\
2.3(0.1)\end{array}$ & $\begin{array}{l}0.9 \mathrm{NS} \\
0.7 \mathrm{NS} \\
0.3 \mathrm{NS} \\
1.0 \mathrm{NS}\end{array}$ & $\begin{array}{l}0.06 \mathrm{NS} \\
0.3 \mathrm{NS} \\
0.9 \mathrm{NS} \\
<0.001\end{array}$ \\
\hline
\end{tabular}

\section{Case review}

Clinical records of 15 patients who were homozygous for the C282Y mutation in HFE and attending the Institute of Liver Studies, King's College Hospital, London were reviewed. In a study of seven patients, a paired design was used to compare phlebotomy treatment before and during administration of a PPI, when this had been administered for at least 12 months. These seven patients represent all those identified and, specifically, no patients who met these criteria were excluded from the analysis. A further eight patients who had never taken a PPI acted as case controls in an unpaired analysis. Of the seven patients in the paired analysis, five had undergone liver biopsy (fibrosis, 3 ; cirrhosis, 2 ) while in the unpaired group, six had undergone liver biopsy (fibrosis, 3; cirrhosis, 3). All liver biopsies showed grade 4 siderosis. ${ }^{16}$ All patients had been fully treated and were undergoing maintenance phlebotomy of $600 \mathrm{ml}$ per session performed at a frequency to maintain serum ferritin $\sim 50 \mu \mathrm{g} / \mathrm{l}^{8}{ }^{9}$ Review was routinely conducted at three-monthly intervals and the serum ferritin and haemoglobin concentration from the previous visit used to inform the decision to carry out phlebotomy. An increase or decrease in the frequency with which phlebotomy was performed was determined by the corresponding change in serial serum ferritin values compared to the target level of $50 \mu \mathrm{g} / \mathrm{l}$. The iron burden at diagnosis was calculated by assuming that $600 \mathrm{ml}$ whole blood contains $\sim 0.25 \mathrm{~g}$ iron and noting the volume of blood removed by the initial course of phlebotomy leading to a reduction in serum ferritin to $\sim 50 \mu \mathrm{g} / \mathrm{l}$ and a transient fall in haemoglobin to between 12 and $13 \mathrm{~g} / \mathrm{dl}$. The long-term use of non-steroidal anti-inflammatory drugs (NSAIDs) was noted. Serum ferritin was measured by immunoassay with chemiluminescent sensing on core equipment (Advia Centaur; Bayer Diagnostics, Newbury, UK) in the Department of Clinical Biochemistry, King's College Hospital.

Statistical analyses were carried out using SPSS, Version 10 for Windows (SPSS Inc, Chicago, IL, USA). The paired Student's $t$ test was used for a within-group comparison of: (1) the number of years used to assess quantity of blood removed before versus during administration of a PPI; (2) average serum ferritin and haemoglobin levels over the course of both recording periods; (3) quantity of blood removed annually to maintain serum ferritin $\sim 50 \mu \mathrm{g} / \mathrm{l}$ during both recording periods. Comparison of these parameters between paired and unpaired groups was performed using one-way ANOVA and an unpaired $t$ test used to compare mean age at the time of analysis.

\section{Post-prandial iron absorption study}

Fourteen patients who were homozygous for the C282Y mutation in HFE and undergoing maintenance phlebotomy took part in a study of the effect of a PPI on the absorption of dietary non-haem iron. Mean age at the time of the study was
57.1 (SE 3.1) years and mean length of time since diagnosis was 8.7 (SE 2.1) years. Liver biopsy performed at diagnosis showed grade 4 siderosis ${ }^{16}$ with fibrosis $(\mathrm{n}=10)$ or cirrhosis $(\mathrm{n}=4)$ and the iron burden calculated as described above was 12.8 (SE 1.8) g. Serum ferritin and haemoglobin concentration at the time of study were 87.8 (SE 14.1) $\mu \mathrm{g} / \mathrm{l}$ and 13.8 (SE $0.4) \mathrm{g} / \mathrm{dl}$ respectively.

We estimated iron absorption by measuring the increase in serum iron concentration after ingestion of a test meal containing highly bioavailable iron, a technique previously validated in individuals who were avid for iron. ${ }^{17}$ The increase in serum iron following ingestion of the meal prepared as a single batch was measured after an overnight fast on two occasions-before and during administration of a PPI daily for 7 days, with patients thereby acting as their own controls. After baseline blood samples had been drawn, patients consumed the meal at a similar time (between 08:30 and 09:15) to avoid possible confounding by diurnal variation in serum iron concentration. The meal has been previously shown to promote absorption (high vitamin C, low polyphenols and phytates) of non-haem iron and consisted of vegetarian shepherd's pie, fruit salad and orange juice. ${ }^{17}$ The meal contained a total of $14.5 \mathrm{mg}$ of iron-comprising $4.5 \mathrm{mg}$ intrinsic iron ${ }^{18}$ and $10 \mathrm{mg}$ extrinsic iron in the form of a $\mathrm{FeCl}_{3}$ solution added to the meal immediately before consumption. ${ }^{17}$

The patients received one of two PPIs, at pharmacoequivalent doses, namely lansoprazole $(30 \mathrm{mg}$ ) or omeprazole $(20 \mathrm{mg})$ daily. Both PPIs increase intragastric $\mathrm{pH}$ to a similar degree and duration over a $24 \mathrm{~h}$ period. ${ }^{19}$ PPIs were taken in the morning for 7 days, starting on the day after the first iron absorption test with the final dose taken on the morning of the second iron absorption test.

Following ingestion of the meal patients were allowed to consume only water for a period of $4 \mathrm{~h}$. During this time, blood was taken every $30 \mathrm{~min}$ for measurement of total serum iron on a Cobas Mira autoanalyzer using a ferrozine-based colorimetric assay ${ }^{20}$ with absorption measured at $562 \mathrm{~nm}$. The parameters of the serum iron curves used as indicators of iron absorption were: the area under the serum iron curve for $4 \mathrm{~h}\left(\mathrm{AUC}_{0-4}\right)$ calculated using the trapezium rule, the maximum increase in serum iron concentration $(\Delta$ iron $\max )$ and percentage iron recovered at peak $(\max ){ }^{.17} \mathrm{~A}$ repeated-measures ANOVA was used to compare the post-prandial increase in total serum iron in patients before and during administration of the PPI using SPSS version 10 .

\section{RESULTS}

\section{Case review}

In the first study, paired data were employed to minimise factors other than a PPI that could have influenced iron stores. Records of blood removed from seven patients during maintenance phlebotomy over an extended period, on average 


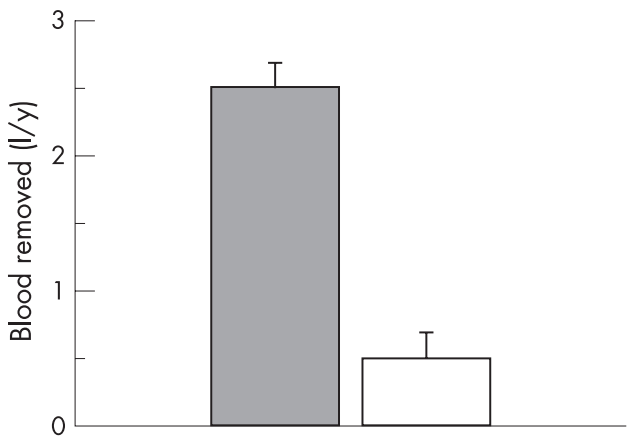

Figure 1 Bar chart showing that the quantity of blood removed annually to maintain serum ferritin at $\sim 50 \mu \mathrm{g} / \mathrm{l}$ in patients with $\mathrm{HH}$ before (filled bar) and during administration of a PPI (open bar) was significantly different $(p<0.001)$. Values are mean $(S E M), n=7$. The recording periods "before" and "during administration" of a PPI were 6.1 (SEM 0.6) years and 3.8 (SEM 0.9) years respectively.

$\sim 10$ years, were available for evaluation, together with repeated haematological and iron biochemical indices. The length of the two recording periods-before and during administration of a PPI-did not differ significantly (table 1 , paired group). In addition, haemoglobin concentration and serum ferritin levels before and during administration of a PPI did not differ significantly (table 1 ) indicating that there was no substantial change in iron stores over the two periods evaluated.

The patients were heavily iron loaded at diagnosis as indicated by marked iron overload on liver biopsy (grade 4 siderosis) and the removal of 14.3 (SEM 5.1) g of iron by the initial course of phlebotomy and it can be anticipated that such patients would require the annual removal of $\sim 4$ units of blood (2-2.5 1) per year to prevent re-accumulation of iron stores. ${ }^{89}$ Annual phlebotomy requirements were found to be 2.5 (SEM 0.25) $\mathrm{l}$ in the period before administration of a PPI (fig l) while administration of a PPI over a $\sim 4$-year period (tables 1 and 2 ) resulted in a significant reduction in the amount of blood removed annually $(0.5$ (SEM 0.25) l, p <0.001) in order to maintain ferritin levels close to the target level of $\sim 50 \mu \mathrm{g} / \mathrm{l}$ (fig 1). The rationale for the administration of a PPI is summarised in table 2 .

In all patients a PPI was administered following upper gastrointestinal endoscopy that was performed because of the development of a new symptom of epigastric pain. Histologically proven Barrett's oesophagus was demonstrated in two patients ( 1 and 4 ) while changes of mild to moderate reflux oesophagitis were found in the remaining patients. This was associated with long-term NSAID use in patients 3 and 7 that was continued while taking a PPI. In all patients upper gastrointestinal endoscopy excluded possible sources of haemorrhage from the oesophagus, stomach and duodenum including varices, portal hypertensive gastropathy and peptic ulceration.

As well as using paired data to investigate the effect of a PPI on iron stores, the records of eight case control patients who had never taken a PPI were also analysed. This unpaired group did not differ significantly when compared with the paired group in terms of mean age (years (SEM)) at time of analysis (55.8 (4.9) vs 63.6 (5.0) (paired), $\mathrm{p}=0.29$ ) or initial iron burden (15.9 (3.9) vs 14.3 (5.1) g (paired), p=1.0). In addition, the length of the recording period, haemoglobin concentration and serum ferritin level $(\mu \mathrm{g} / \mathrm{l})$ did not differ significantly when compared with the paired group, either before or during a PPI (table 1). Annual phlebotomy requirements for the unpaired group compared with the paired group before PPI did not differ significantly, while, as expected, there

\begin{tabular}{|c|c|c|c|}
\hline Patient & $\begin{array}{l}\text { Proton pump } \\
\text { inhibitor }\end{array}$ & $\begin{array}{l}\text { Duration of use } \\
\text { (years) }\end{array}$ & Reason for use \\
\hline $\begin{array}{l}1 \\
2 \\
3 \\
4 \\
5 \\
6 \\
7\end{array}$ & $\begin{array}{l}\text { Omeprazole } 20 \mathrm{mg} \\
\text { Lansoprazole } 30 \mathrm{mg} \\
\text { Omeprazole } 20 \mathrm{mg} \\
\text { Omeprazole } 20 \mathrm{mg} \\
\text { Omeprazole } 20 \mathrm{mg} \\
\text { Lansoprazole } 15 \mathrm{mg} \\
\text { Lansoprazole } 15 \mathrm{mg}\end{array}$ & $\begin{array}{l}3 \\
1 \\
4 \\
5 \\
8 \\
4 \\
1.5 \\
3.8(0.9)^{*}\end{array}$ & $\begin{array}{l}\text { Barrett's oesophagus } \\
\text { GORD } \\
\text { GORD } \\
\text { Barrett's oesophagus } \\
\text { GORD } \\
\text { GORD } \\
\text { GORD }\end{array}$ \\
\hline
\end{tabular}

GORD, gastro-oesophageal reflux disease.

*Mean (SEM).

was a highly significant reduction when compared with the paired group during PPI (table 1). It is unlikely that increased age played a part in this reduction, because the mean age of the paired group while on the PPI did not differ significantly from the unpaired group and yet phlebotomy requirements were significantly reduced (table 1 ).

\section{Post-prandial iron absorption study}

Fourteen fully treated patients took part in an investigation of the effect of a PPI on iron absorption. Serum iron curves were generated on two occasions following ingestion of a meal containing highly bioavailable non-haem iron, the first before taking a PPI and the second a week later, having taken a PPI for 7 days. As shown in figure 2 the presence of a PPI resulted in a significant reduction $(p<0.01)$ in the maximum increase in serum iron concentration ( $\Delta$ iron max) following ingestion of the meal. Administration of a PPI led to a significant reduction $(p<0.01)$ in other parameters, namely the area under the serum iron curve for $4 \mathrm{~h}\left(\mathrm{AUC}_{0-4}\right)$ and \% recovery of administered iron at peak $(\max )$, that were derived from the serum iron curves and used as indicators of iron absorption (table 3 ).

\section{DISCUSSION}

Our investigations suggest that administration of a PPI to patients with $\mathrm{HH}$ can inhibit absorption of dietary non-haem iron, and limit the accumulation of iron in tissue stores.

The advantage of measuring serum iron increase after ingestion of oral iron is that it directly addresses the issue of iron absorption rather than erythrocyte use as shown by most isotope-based techniques (see reference 17 for discussion). We have demonstrated a significant PPI-related reduction in the absorption of non-haem iron in patients with $\mathrm{HH}$, and this, together with our observation that there was a significant reduction in phlebotomy requirements in patients taking PPIs over a long period, suggests that gastric acid suppression can inhibit the absorption of non-haem iron from the habitual diet in $\mathrm{HH}$.

Non-haem iron, of which the majority is in the ferric form, ${ }^{21}$ supplies at least two thirds of dietary iron requirements and the availability of iron in this pool, unlike that in the haem pool, is critically dependent on meal composition and other factors operating in the stomach and duodenum. ${ }^{11}{ }^{22}$ Of these, gastric hydrochloric acid $(\mathrm{HCl})$ is the most important luminal factor acting to promote optimum absorption by reducing ferric iron to the more soluble ferrous form, aiding in the release of iron from food matrices and facilitating chelation in the stomach of remaining ferric iron by ascorbic acid, sugars and amino acids. ${ }^{11}$ The role of the $\mathrm{pH}$ of gastric juice in the solubilisation and absorption of non-haem food iron, as determined by gastric $\mathrm{HCl}$, has been previously investigated in normal subjects and patients with idiopathic haemochromatosis using combined in vitro and in vivo approaches. In vitro experiments investigating 


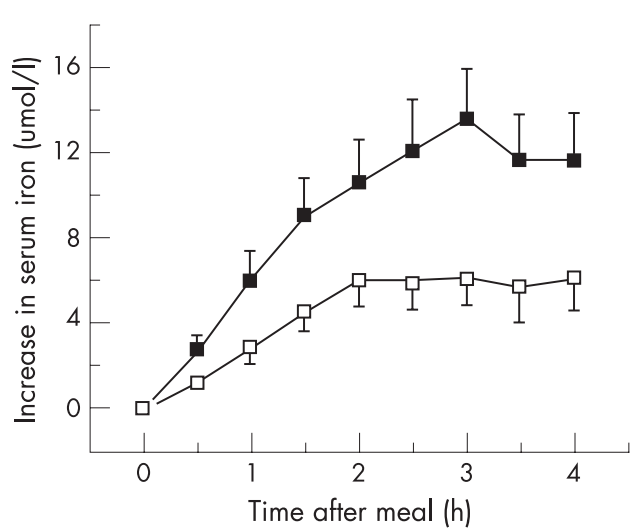

Figure 2 Serum iron curves were generated following ingestion of a meal containing non-haem iron (14.5 mg) before (closed squares) and at the end of a $7 \mathrm{~d}$ course of a PPI (open squares). Values are means (SEM), $n=14$. PPI resulted in a significant reduction (all $p<0.01$ ) in (i) maximum increase in serum iron concentration ( $\Delta$ iron max), (ii) area under the serum iron curve over $4 \mathrm{~h}\left(\mathrm{AUC}_{0-4}\right)$, and (iii) percentage of administered iron recovered at peak (max).

the capacity of gastric juice produced by pentagastrin challenge, to release radioiron through solubilisation from biosynthetically labelled bread, showed that below pH 2.5 there was a linear relation between $\mathrm{pH}$ and percentage solubility. ${ }^{23}$ In contrast, samples of gastric juice with $\mathrm{pH}$ values above 2.5 released negligible amounts of iron, whereas in linked, in vivo studies a close correlation was demonstrated between iron absorption and the capacity of gastric juice to release food iron in both controls and patients. The finding that above $\mathrm{pH} 2.5$ there was a failure to solubilise and absorb non-haem iron ${ }^{23}$ is highly relevant to the current study because PPIs are potent inhibitors of gastric acid; for example, the administration of $20 \mathrm{mg}$ omeprazole daily leads to an intragastric $\mathrm{pH}$ of $>4$ for at least $8 \mathrm{~h}$ in $67 \%$ of individuals and a median intragastric $\mathrm{pH}$ over $24 \mathrm{~h}$ of $>3.6 .^{24}$ At these levels of gastric acidity, negligible amounts of non-haem iron would be released from dietary components $^{23}$ and reduction of ferric iron and formation of ferric chelates would be impaired. ${ }^{11}$ This would have a major impact on iron absorption because ferrous iron and ferric chelates normally remain soluble in the alkaline environment of the bulb/post bulbar regions, ${ }^{25}{ }^{26}$ facilitating the transport of iron across the intestinal epithelium by mucosal iron transporters and accessory proteins. ${ }^{21}$

Iron absorption consists of an uptake step in which iron is transported across the apical membrane of the enterocyte, and transfer, the movement of iron across the basolateral membrane into the portal circulation. ${ }^{21}$ The apical and basolateral transporters have recently been identified as divalent metal transporter 1 (DMT1) and ferroportin respectively, (reviewed in Pietrangelo $^{1}$ and Bomford ${ }^{2}$ ) and, furthermore, the duodenal expression of both carriers is increased in $\mathrm{HH}^{.7-29}$ The increase in ferroportin expression is caused by a relative lack of the iron regulatory hormone hepcidin, a peptide that regulates cellular iron efflux by binding to ferroportin and inducing its internalisation..$^{30}$ Hepcidin is deficient in both treated and untreated $\mathrm{HH}^{31}{ }^{32}$ resulting in uncontrolled activity of ferroportin and increased efflux of iron from the enterocyte. While low levels of intracellular iron in the enterocyte could result in increased expression of the apical transporter, by stabilising mRNA transcripts through enhanced binding of iron-responsive protein to the $3^{\prime}$ iron-responsive element, this is not known with certainty. ${ }^{27}$ In spite of the increased activity and expression of iron transporters and the powerful stimulus to iron absorption provided by phlebotomy, ${ }^{33}$ iron absorption and tissue iron accumulation can be significantly reduced by administration of a PPI. This contrasts with tea drinking which significantly inhibits iron absorption from a test meal but has only a modest effect on phlebotomy requirements needed to maintain normal iron balance. ${ }^{10}$ PPIs, being powerful inhibitors of gastric acid, disrupt the speciation of dietary iron and this may be a more effective way of inhibiting non-haem iron absorption than by binding luminal iron with polyphenols present in tea.

Long-term use of PPIs has not been reported to compromise iron status in normal subjects, ${ }^{14}{ }^{15}$ possibly because individuals with intact regulatory mechanisms of iron absorption are able to adapt to impaired bioavailablity of non-haem iron. One interpretation of our results is that such adaptation does not occur in $\mathrm{HH}$. These patients demonstrate an expression profile of mucosal iron transporters ${ }^{27}$ and iron absorption kinetics more in common with iron deplete than with iron replete individuals, ${ }^{34-36}$ and, as a result may not be able to further increase iron absorption. Nevertheless, our finding that patients with $\mathrm{HH}$ who were taking a PPI still required the removal of 0.5 (0.2) l of blood annually to maintain normal iron balance suggests that an additional source of iron was available in the habitual diet. We would argue that this was likely to be haem iron because absorption of this form of iron is not dependent on gastric $\mathrm{HCl}^{34} 37$ and, furthermore, is increased in haemochromatosis. ${ }^{34}$ It is also possible that absorption of haem iron plays an important role in ensuring dietary iron availability in normal subjects on a long-term PPI. Further investigation of this question would be possible using the study design described here.

Phlebotomy remains the mainstay of treatment and is well tolerated by the majority of patients with $\mathrm{HH}$, although for some the procedure is burdensome because of pain and discomfort and disruption to their daily routine. ${ }^{38}$ In addition, a minority of patients have such poor venous access that even intermittent phlebotomy becomes an intolerable burden. Our observations suggest that administration of a low-dose PPI, a class of compounds that have an excellent long-term safety profile, could be a useful adjunct to phlebotomy in the management of $\mathrm{HH}$, particularly as patient compliance deteriorates over time. ${ }^{39}$ Finally, the pharmacological control of gastric acid secretion should be explored as a simple means of limiting iron overload in conditions such as thalassaemia intermedia and pyruvate kinase deficiency in which erythroid expansion can lead to a 5-10-fold increase in iron absorption and a marked increase in tissue iron stores and in whom phlebotomy is not possible because of severe anaemia. ${ }^{40}$

Table 3 Parameters derived from serum iron curves and used as indicators of iron absorption

\begin{tabular}{llll}
\hline & $\begin{array}{l}\text { Area under the serum curve } \\
\left(\text { AUC }_{0-4}\right)\end{array}$ & $\begin{array}{l}\text { Maximum increase in serum iron \% recovery of iron at peak } \\
(\Delta \text { iron max) }\end{array}$ \\
\hline (max)
\end{tabular}

*All values are mean $(S E M), n=14$. 


\section{ACKNOWLEDGEMENTS}

We thank Kelly Gleason and Wendy Williams for their help with the iron absorption studies and staff in the department of Clinical Biochemistry, King's College Hospital for analysing total serum iron.

\section{Authors' affiliations}

C Hutchinson, C A Geissler, A Bomford, The Iron Metabolism Interdisciplinary Research Group, King's College London, London, UK J J Powell, MRC Human Nutrition Research, Cambridge, UK

Competing interests: None.

\section{REFERENCES}

1 Pietrangelo A. Hereditary hemochromatosis: a new look at an old disease. N Engl J Med 2004;350:2383-97.

2 Bomford A. Genetics of haemochromatosis. Lancet 2002;360:1673-81.

3 Davis WD Jr, Arrowsmith WR. The effect of repeated phlebotomies in hemochromatosis; report of three cases. J Lab Clin Med 1952;39:526-32.

4 Powell LW. Changing concepts in haemochromatosis. Postgrad Med J 1970:46:200-9.

5 Bomford A, Williams R. Long term results of venesection therapy in idiopathic haemochromatosis. Q J Med 1976;45:611-23.

6 Niederau C, Fischer R, Purschel A, et al. Long-term survival in patients with hereditary hemochromatosis. Gastroenterology 1996;1 10:1107-19.

7 Niederau C, Fischer R, Sonnenberg A, et al. Survival and causes of death in cirrhotic and non-cirrhotic patients with primary hemochromatosis. N Engl J Med 1985;313:1256-62.

8 Tavill AS, American Association for the Study of Liver Diseases, American College of Gastroenterology, American Gastroenterological Association. Diagnosis and management of hemochromatosis. Hepatology 2001;33:1321-8.

9 Dooley J, Worwood M. Guidelines on diagnosis and therapy: genetic haemochromatosis. British Committee for Standards in Haematology, 2000:1-33.

10 Kaltwasser JP, Werner E, Schalk K, et al. Clinical trial on the effect of regular tea drinking on iron accumulation in genetic haemochromatosis. Gut 1998:43:699-704.

11 Champagne ET. Low gastric hydrochloric acid secretion and mineral bioavailability. Adv Exp Med Biol 1989;249:173-84.

12 Sharma VR, Brannon MA, Carloss EA. Effect of omeprazole on oral iron replacement in patients with iron deficiency anemia. South Med J 2004;97:887-9.

13 Skikne BS, Lynch SR, Cook JD. Role of gastric acid in food iron absorption. Gastroenterology 1981;81:1068-71.

14 Koop H, Bachem MG. Serum iron, ferritin, and vitamin $B_{12}$ during prolonged omeprazole therapy. J Clin Gastroenterol 1992;14:288-92.

15 Stewart CA, Termanini B, Sutliff VE, et al. Iron absorption in patients with Zollinger-Ellison syndrome treated with long-term gastric antisecretory therapy. Aliment Pharmacol Ther 1998;12:83-98.

16 Schever PJ, Williams R, Muir AR. Hepatic pathology in relatives of patients with haemochromatosis. J Pathol Bacterio 1962:84:53-64.

17 Conway RE, Geissler CA, Hider RC, et al. Serum iron curves can be used to estimate dietary iron bioavailability in humans. J Nutr 2006;136:1910-14.
18 Holland B, Welch AA, Unwin ID, et al. McCance and Widdowson's The composition of foods. Fifth edition. London: The Royal Society of Chemistry and Ministry of Agriculture, Fisheries and Foods, 1991.

19 Miner P Jr, Katz PO, Chen Y, et al. Gastric acid control with esomeprazole, lansoprazole, omeprazole, pantoprazole, and rabeprazole: a five-way crossover study. Am J Gastroenterol 2003;98:2616-20.

20 Ruutu R. Determination of iron and unsaturated iron binding capacity in serum with ferrozine. Clinica chimica acta 1975;61:229-32.

21 Miret S, Simpson RJ, McKie AT. Physiology and molecular biology of dietary iron absorption. Annu Rev Nutr 2003;23:283-301.

22 Hallberg L. Bioavailability of dietary iron in man. Annu Rev Nutr $1981 ; 1: 123-47$.

23 Bezwoda W, Charlton R, Bothwell T, et al. The importance of gastric hydrochloric acid in the absorption of nonheme food iron. J Lab Clin Med 1978;92:108-16.

24 Lind T, Rydberg L, Kyleback A, et al. Esomeprazole provides improved acid control vs. omeprazole in patients with symptoms of gastro-oesophageal reflux disease. Aliment Pharmacol Ther 2000;14:861-7.

25 Archambault AP, Rovelstad RA, Carlson HC. In situ pH of duodenal bulb contents in normal and duodenal ulcer subjects. Gastroenterology 1967;52:940-7.

26 Schade SG, Cohen RJ, Conrad ME. Effect of hydrochloric acid on iron absorption. N Engl J Med 1968;279:672-4.

27 Zoller H, Koch RO, Theurl T, et al. Expression of the duodenal iron transporters divalent-metal transporter 1 and ferroportin 1 in iron deficiency and iron overload. Gastroenterology 2001;120:1412-19.

28 Griffiths WJ, Sly WS, Cox TM. Intestinal iron uptake determined by divalent metal transporter is enhanced in HFE-deficient mice with hemochromatosis. Gastroenterology 2001;120:1420-9.

29 Stuart KA, Anderson GJ, Frazer DM, et al. Duodenal expression of iron transport molecules in untreated haemochromatosis subjects. Gut 2003;52:953-9.

30 Nemeth E, Tuttle MS, Powelson J, et al. Hepcidin regulates cellular iron efflux by binding to ferroportin and inducing its internalization. Science 2004;306:2090-3.

31 Bridle KR, Frazer DM, Wilkins SJ, et al. Disrupted hepcidin regulation in HFErelated haemochromatosis and the liver as a regulator of body iron homoeostasis. Lancet 2003;361:669-73.

32 Gehrke SG, Kulaksiz H, Herrmann T, et al. Expression of hepcidin in hereditary hemochromatosis: evidence for a regulation in response to serum transferrin saturation and non-transferrin-bound iron. Blood 2003;102:371-6.

33 Williams R, Manenti F, Williams HS, et al. Iron absorption in idiopathic haemochromatosis before, during, and after venesection therapy. BMJ 1966:2:78-81.

34 Lynch SR, Skikne BS, Cook JD. Food iron absorption in idiopathic hemochromatosis. Blood 1989;74:2187-93.

35 Powell LW, Campbell CB, Wilson E. Intestinal mucosal uptake of iron and iron retention in idiopathic haemochromatosis as evidence for a mucosal abnormality. Gut 1970;11:727-31.

36 Marx JJM. Mucosal uptake, mucosal transfer and retention of iron, measured by whole-body counting. Scand J Haematol 1979;23:293-302.

37 Turnbull A, Cleton F, Finch CA. Iron absorption. IV. The absorption of hemoglobin iron. J Clin Invest 1962;41:1897-07.

38 Seamark CJ, Hutchinson M. Controversy in primary care: should asymptomatic haemochromatosis be treated? BMJ 2000:320:1314-17.

39 Hicken BL, Tucker DC, Barton JC. Patient compliance with phlebotomy therapy for iron overload associated with hemochromatosis. Am J Gastroenterol 2003:98:2072-7.

40 Porter JB. Practical management of iron overload. Br J Haematol $2001 ; 115: 239-52$ 